\title{
Chemical Ablation of the Soft Palate Neoplasm
}

\author{
ALEXANDRU DUMITRAS MEIUS ${ }^{1}$, TEODORA IOANA GHINDEA ${ }^{3}$, CATALINA PIETROSANU ${ }^{1}$, DRAGOS CRISTIAN STEFANESCU ${ }^{1}$, \\ IRINA IONITA ${ }^{1,2 *}$, ANDREEA RUSESCU ${ }^{1}$, VIOREL ZAINEA ${ }^{1,2}$, RAZVAN HAINAROSIE ${ }^{1,2}$ \\ ${ }^{1}$ Carol Davila University of Medicine and Pharmacy, $8^{\text {th }}$ Eroii Sanitari Blvd., 050474, Bucharest, Romania \\ 2Prof. Dr. D. Hociota Institute of Phonoaudiology and Functional ENT Surgery, 21 Mihail Cioranu Str., 050751, Bucharest, \\ Romania \\ ${ }^{3}$ CMDTAMP, 8-10 Washington Str., 011794, Bucharest, Romania
}

\begin{abstract}
Approximately $2 \%$ of head and neck malignancies are represented by tumors of the soft palate. The main risk factors associated are smoking, alcohol abuse, human papilloma virus infections, poor oral hygiene, mechanical irritation. The treatment of the soft palate cancer depends on the staging of the tumor and of the pathologic type of the carcinoma. In this article, we will present coblation under endoscopic control as a new method of resection of the soft palate neoplasms.
\end{abstract}

Keywords: soft palate neoplasm, endoscopic surgery, coblation

The oral cavity is separated from the nasal cavity and the maxillary sinuses by the palate. The palate's mucosa is a keratinizing pseudostratified squamous epithelium, and the submucosa contains minor salivary grands, mainly in the hard palate area. The palatine bone's periostium is a barrier to the spread of cancer. The palatine foramina located near the third molar represents a pathway for the neurovascular supply but also for the tumors to spread. The blood supply for this region is represented by the maxillary artery [1].

The soft palate is part of the oral pharynx, and it consists of mucosa on both of its surfaces, and in between these surfaces, there are muscle fibers, blood vessels, lymphatic vessels, minor salivary glands and connective tissue. Its function is to separate the oropharynx from the nasopharynx during speech and swallowing. It prevents regurgitation when swallowing and air escape during speech [1,2].

Approximately $2 \%$ of head and neck malignancies are represented by tumors of the soft palate. From these tumors, $80 \%$ are squamous cell carcinomas and $20 \%$ nonsquamous cell carcinomas. The main risk factors associated are smoking, alcohol abuse, human papilloma virus infections, poor oral hygiene, mechanical irritation $[3,4]$.

In the early stages patients are asymptomatic, but in advanced stages, symptoms like pain appear. Other symptoms of malignant tumors of the palate are bleeding, loose teeth, a palate tumoral mass or foul odor, and in advanced stages velopharyngeal insufficiency, the difficulty of speech and swallowing, trismus, otalgia or neck adenopathy $[5,6]$.

Tumors in this region are usually found in early stages because of the good visualization of the area [5].

The diagnosis is based on the clinical examination of the patient, endoscopic examination, radiological investigations and biopsy $[7,8]$.

The CT radiologic evaluation increases the accuracy of staging and assesses bone invasion and extension of the tumor to the nasal fossa, maxillary sinuses, skull base, pterygoid plates and muscles, infratemporal fossa and masticator space.

MRI is usually needed for the visualization of the perineural extension along the palate foramina and for patients with intracranial involvement to assess dural invasion.
Pulmonary and abdominal CT scans should be performed in advanced stages when there is a high risk of metastasis [9].

A biopsy is required for the positive diagnosis of the lesion, and it can be performed under local anesthesia [10].

In the case of ulcerative lesions, the biopsy should be performed close to the edge of the tumor to avoid necrotic tissue[11].

The stadialisation of the oropharyngeal cancer is:

The tumor:

TX: Primary tumor cannot be assessed TO No evidence of primary tumor

Tis: Carcinoma in situ

T1: Tumor $2 \mathrm{~cm}$ or less in greatest dimension

T2: Tumor more than $2 \mathrm{~cm}$ but not more than $4 \mathrm{~cm}$ in greatest dimension

T3: Tumor more than $4 \mathrm{~cm}$ in greatest dimension or extension to lingual

surface of epiglottis

T4a :Moderately advanced local disease

Tumor invades the larynx, deep/extrinsic muscle of the tongue, medial pterygoid, hard palate, or mandible

T4b: Very advanced local disease

Tumor invades the lateral pterygoid muscle, pterygoid plates, lateral nasopharynx, or skull base, or encases the carotid artery

Regional lymph nodes:

Nx Regional lymph nodes cannot be assessed NO No regional nodes metastasis

N1 Metastasis in a single ipsilateral lymph node, $3 \mathrm{~cm}$ or less in greatest dimension

N2 Metastasis in a single ipsilateral lymph node, more than $3 \mathrm{~cm}$ but not more than $6 \mathrm{~cm}$ in greatest dimension; or in multiple ipsilateral lymph nodes, none more that 6 $\mathrm{cm}$ in greatest dimension; or in bilateral or contralateral lymph nodes, none greater than $6 \mathrm{~cm}$ in greatest dimension

N2a Metastasis in a single ipsilateral lymph node, more than $3 \mathrm{~cm}$ but not more than $6 \mathrm{~cm}$ in greatest dimension

N2b Metastasis in multiple ipsilateral lymph nodes, none more that $6 \mathrm{~cm}$ in greatest dimension

N2c Metastasis in bilateral or contralateral lymph nodes, none more than $6 \mathrm{~cm}$ in greatest dimension

N3 Metastasis in a lymph node more than $6 \mathrm{~cm}$ in greatest dimension.

Distant metastasis

Mx Distant metastasis cannot be assessed

* email: irinaroshu@yahoo.com; Phone: 0040721241122

All authors have contributed equally to this paper. 


\section{M0 No distant metastasis}

M1 Distant metastasis [12]

Approximately $25 \%$ of patients with soft palate cancer have synchronous or metachronous lesions. That is why panendoscopy, esophagoscopy, bronchoscopy and laryngoscopy should be performed on this patients [13,14].

The treatment of the soft palate cancer depends on the staging of the tumor and of the pathologic type of the carcinoma.

Midline tumors and the ones that extend across the palatine arch have poor survival rates because of a higher incidence of metastasis. Due to the soft palate's functions, surgery in this area is challenging because it can affect both speech and swalloing. In the past, the radiotherapy was the recommended treatment for this pathology, but with the advances of the technology and the reconstructive techniques, nowadays effective surgiucal resections can be performed for these patients $[15,16]$.

Because of the high rate of regional metastasis, the treatment must include the regional lymphatic nodes of the soft palate. The surgery is performed under general anaesthesia. The patient is placed in a supine position with the head extended. For smaller tumours the most frequent approach is transoral, but for advanced stages, mandibulotomy is performed to provide a wide exposure of the operating field. Nowadays the advances of the surgical devices created new methods of the tumor resection that are minimally invasive and reduce postoperative complications like velopharyngeal insufficiency, hipernasal speech, Eustachian tube scarring or disfagia [17].

In this article, we will present coblation as a new method of resection of the soft palate neoplasms.

\section{Experimental part}

Coblation is a new and minimally invasive technology that is used for the dissection and ablation of soft tissue. This system uses radiofrequency combined with a saline solution for ablation, but it can also perform coagulation. However, the tissues and the adjacent structures suffer not thermal lesions because coblation is a non-heat technology[18].

The components of the coblator system are the controller, the foot pedal and the wand cable. There are many types of wands available for coblation in different anatomical regions. According to the type of wand connected to the controller, default settings for that specific wand appear on display [19].

For the ablation of soft palate tumors, we used the Procise XP coblation wand. This tyoe of wand generates a plasma field through its shaft placed at the tip of the wand. The plasma field is formed when radiofrequency energy passes through the saline solution and brakes it into ions. The function of the plasma field is to dissociate the molecullar bonds of the soft tissue, causing dissolution. The Procise XP wand has a lower-profile shaft, well suited for small anatomical regions and has integrated sucction, ablation and coagulation features. These features help to decrease surgical time [19].

In our clinic, we performed chemical ablation of the soft palate neoplasm with the patient under general anaesthesia, and we used the $0^{\circ}$ rigid endoscopic tube for better visualization of the region and the lesion. A special mouth gag was used to provide better exposure of the operating field. The procise XP wand, with the help of the special irrigation system, can be oriented in any way needed for it not to obstuct the surgeon's visualization of the surgical field (fig. 1).

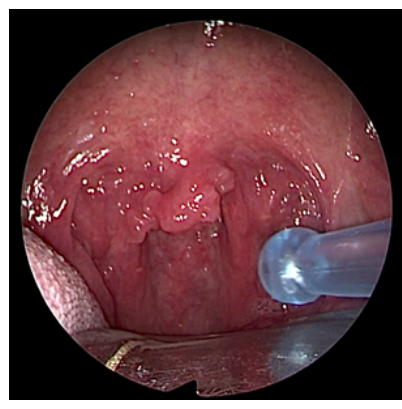

Fig. 1. Intraoperative image of the soft palate neoplasm

We performed the resection of the soft palate carcinoma with minimum bleeding (fig.2, fig. 3).

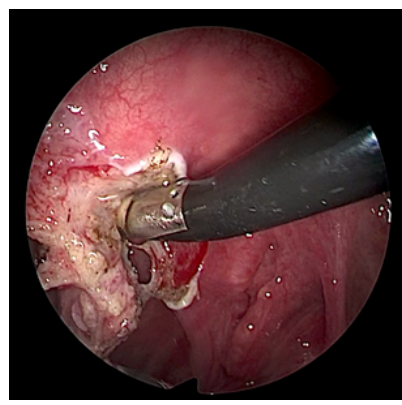

Fig. 2. Chemical ablation of the soft palate neoplasm

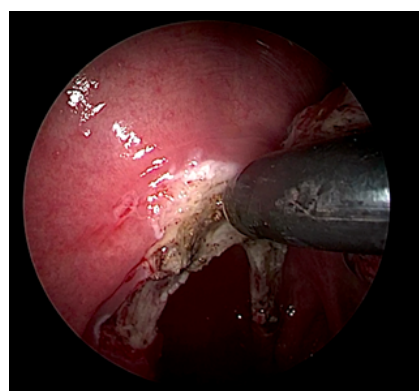

Fig. 3 Chemical ablation of the soft palate neoplasm

A wide resection was made in order to obtain negative margins and to prevent reccurence (fig. 4).

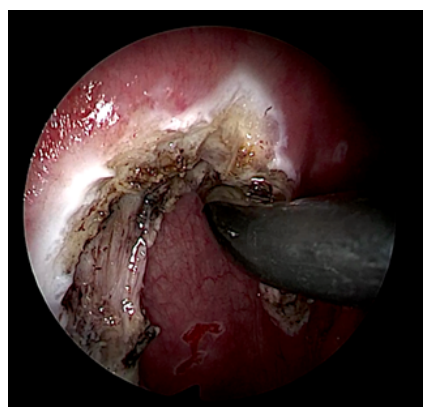

Fig. 4. Intraoperative image after complete ablation of the tumor

\section{Results and discussions}

The soft palate's main functions are preventing nasofaryngeal regurgitation during swalloing and air escape into the nose during speech. Because of this, the surgical management of the tumours located in this area represents a challenge for the surgeon.

The main postoperative complications are velopharyngeal insufficiency, hypernasal speech, dysphagia and loss of function of the tensor or levator palatini muscles. The extent of the complications depends on the extent of the resection, the size of the defect and the method of reconstruction.

Because adequate reconstruction is difficult to achieve, in the past radiation therapy was the treatment of choice for these tumors.

The classical surgical method for the resection of soft palate tumors is performed with cold instruments which may lead to intraoperative heavy bleeding. Hemostasis is achieved with the bipolar cautery which causes thermal damage to the tissues. 
A modern and effective surgical method for the resection of the soft palate carcinomas with good outcomes and reduced complications is coblation. The procedure is minimally invasive with minimum bleeding during the surgery and with no thermal lesions of the surrounding tissue. In case of heavy bleeding during the surgery, the coagulation feature provides fast and efficient hemostasis.

Due to the wands' multiple functions, surgical time dicreases and due to its low-profile malleable shaft, the visualization of the surgical field is increased. This ensures the complete resection of the tumour.

Coblation performed under endoscopic control reduces the incidents of Eustachian tube lesions and scarring that can cause middle ear effusion.

After surgery, oncological therapy is required, which may include radiation and chemoterapy.

\section{Conclusions}

We consider chemical ablation of the soft palate neoplasm to be an advantageous surgical method because it is minimally invasive and with the help of the Procise XP wand, that has sucction, ablation and coagulation integrated all in one, it reduces surgical time.

The visibility of the surgical field throughout the intervention is increased, allowing the surgeon to completely remove the tumour mass with safety margins.

Postoperative recovery of the patient is faster, and the hospital stay is decreased.

\section{References}

1.HOLLINSHEAD, W.H., Anatomy for Surgeons. The Head and Neck. 3rd ed. Philadelphia, Pa: Lippincott Williams \& Wilkins, 1982, p. 33145.

2.PITURU, T.S., BUCUR, A., GUDAS, C. et al.,J ournal Of CranioMaxillofacial Surgery,44,nr.4,2016,p.500-505.

3.CHUNG, C.K., CONSTABLE, W,C. Int J Radiat Oncol Biol Phys, 5,nr.6, 1979, p. 845-50.

4.GRAHAM, S., DAYAL, H., ROHRER, T., et al. J Natl Cancer Inst, 59,nr.6, 1977, p. 1611-8.
5.RUSS, J.E., APPLEBAUM, E.L., SISSON, G.A. Laryngoscope 87,nr7, 1977, p. 1151-6.

6.LEBLEBICIOGLU, H., ARAMA,V., CAUSSE, X., J ournal Of Viral Hepatitis,21,nr.9,2014,p. 662-670.

7.LEIPZIG, B., ZELLMER, J.E., KLUG, D. Arch Otolaryngol, 111,nr.9, 1985 p. 589-94.

8.MAZILU, L., NICULESCU, Z., SUCEVEANU, A.I. etal., Revista Romana De Bioetica ,8,nr.3,2010,p.181-188.

9.KATO, H., KANEMATSU, M., MAKITA, H., et al. Eur J Radiol, 83, 2014, p. 137-146.

10.AVON, S.L., KLIEB, H.B. J Can Dent Assoc, 2012, p. 75-78.

11.J ELIHOVSCHI, I., DROCHIOI, C.,BADESCU, A.C., et al ,Comparison of Sampling Techniques For qPCR Quantification of Periodontal Pathogens, Rev. Chim.(Bucharest), 68,no.12,2017,p. 2853-2856.

12.MARVARETTA, M., STEVENSON, M.D., PETRUZZELLI, G.J . Head and Neck. American J oint Committee on Cancer. AJCC Cancer Staging Manual. 8th ed. New York, NY: Springer, 2016.

13.RODRIGUEZ-BRUNO, K., ALI, M.J., WANG, S.J . Head Neck., 33,nr.7, 2011, p. 949-53.

14.CIOCIRLAN, M.,DRAGHIA, L., MANUC, D.,t al., Conference: 3rd International Conference on Interdisciplinary Management of Diabetes Mellitus and its Complications (Interdiab),Interdiab 2017: Diabetes Mellitus In Internal Medicine, Book Series: International Conference on Interdisciplinary Management of Diabetes Mellitus and its Complications,2017, p.132-138.

15.GILLESPIE, M.B., BRODSKY, M.B., DAY, T.A., et al. Laryngoscope, $114, \mathrm{nr} .8,2004$, p. 1362-7.

16.NITIPIR, C., NICULAE, D.,ORLOV, C. et al., Oncology Letters,14,nr.6,2-17,p.7011-7015.

17.PANJE, W.R., MORRIS, M.R. NAUMANN, H.H., HELMS, J., HERBERHOLD, C., JAHRSDOERFER, R.A., KASTENBAUER, E.R., PANJE, W.R., TARDY J r., M.E. Surgery of oral cavity, tongue, and oropharynx. Head and Neck Surgery. New York, NY: Thieme, 1995, p. 739-53.

18.W OLOSZKO, J., GILBRIDE, C., SUNNYVALE, C.A., Arthrocare Corp, 2000

19.BELOV, S. V., Biomedical Engineering, 38, nr. 2, 2004, p. 80-85.

$\overline{\text { Manuscript received:16.08.2018 }}$ 